Case Report

\title{
Untreated Anderson Type II Odontoid Fracture with Severe Delayed Atlanto-Axial Dislocation, Lateral Mass Misleading Signs of Fusion, and Posterior Surgical Approach: A Case Re- port
}

\author{
V. Chiarella , U. A. Arcidiacono, G. Santoro*, A. Di Bartolomeo, M. Giugliano, A. G. Ruggeri \\ Department of Human Neurosciences, Neurosurgery, Sapienza University, Rome, Italy \\ ${ }^{*}$ Correspondence: G. Santoro, giorgio8480@gmail.com
}

How to cite this paper: Chiarella, V., Arcidiacono, U. A., Santoro, G., Di Bartolomeo, A., Giugliano, M., \& Ruggeri, A. G. (2022). Untreated Anderson Type II Odontoid Fracture with Severe Delayed Atlanto-Axial Dislocation, Lateral Mass Misleading Signs of Fusion, and Posterior Surgical Approach: A Case Report. Universal Journal of Neuroscience, 1(1), 36. Retrieved from https://www.scipublications.com/journal/index.php/ujn/article/view/189

Received: November 29, 2021 Accepted: February 21, 2022 Published: February 22, 2022

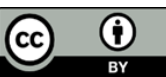

Copyright: (c) 2022 by the authors. Submitted for possible open access publication under the terms and conditions of the Creative Commons Attribution (CC BY) license (http://creativecommons.org/licenses /by/4.0/).

\begin{abstract}
We present a case of untreated type II odontoid fracture, which evolved in severe dislocation 18 months later. Delayed dislocations in untreated type II odontoid fractures are already reported in literature. The singularity of our case is that CT-scan showed signs of fusion in the right C1-C2 articulation, which could have required a more complex surgical procedure to realign the upper cervical spine. Surprisingly, a CT scan performed in the extension position showed complete mobility of $\mathrm{C} 1$ and allowed us to perform a one stage posterior fixation. We want to highline both the importance of treating an Anderson type II fracture to prevent dislocation (acute or delayed), and the possibility to perform a flexion-extension CT scan to project a better surgical plan.
\end{abstract}

Keywords: Anderson, Goel-Harms, Odontoid, Dislocation, Realignment, Fracture

\section{Introduction}

Despite the frequency of odontoid Anderson type II fracture, there are controversies about optimal management strategy in this condition. Some authors presented an algorithm to help the surgeon in the decision process. [1] Strategies include surgery and external immobilization, and results of both strategies and relative outcomes are presented in literature.[2,3] We present a case of untreated type II odontoid fracture, which evolved in severe dislocation 18 months later. Delayed dislocations in untreated type II odontoid fractures are already reported in literature.[4,5] The singularity of our case is that CT-scan showed signs of fusion in the right C1-C2 articulation, which could have required a more complex surgical procedure to realign the upper cervical spine. This case was written according to the CARE statement guidelines, and the patient gave her consent to this publication.[6]

\section{Case Presentation}

A 60-year-old woman came to our Emergency Department complaining of worsening neck pain in the last 6 months. She had a car accident 18 months earlier, after which a cervical fracture was diagnosed. She did not remember which vertebra was involved and had not any documentation, since she was in a foreign hospital at the time and was discharged without receiving any prescription of treatment. The physical examination was normal, except for neck pain, rated 6/10 in Visual Analogue Scale. No comorbidities were referred, apart hypertension under treatment. She underwent a cervical CT scan (Figure 1) showing Anderson type II odontoid fracture with severe atlanto-axial anterior dislocation and fusion signs in the right C1-C2 articulation. The overall bone density of cervical bone structures was normal. A cervical MRI was performed, showing no compression on 
the neural elements. No ossifications of alar or transverse ligaments were noticed. AngioCT scan showed good perfusion of both vertebral arteries.
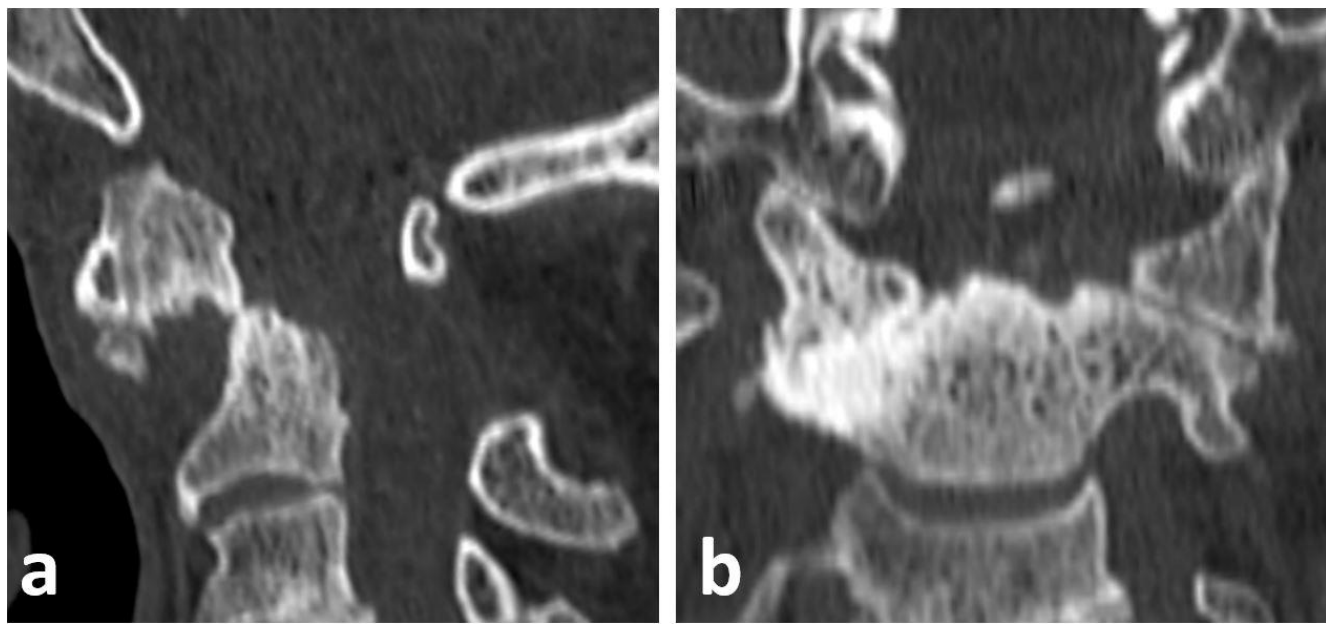

Figure 1. Cervical CT scan performed at the arrival to our institution, 18 months after trauma. a) On sagittal plane is visible the severe dislocation of $\mathrm{C} 1$ and odontoid process. b) On coronal plane, signs of sclerosis and bone fusion are visible in right $\mathrm{C} 1-\mathrm{C} 2$ articulation.

To develop a surgical planning, the patient underwent, under strict neurosurgical control, a new cervical CT scan in both head-neck flexion and extension (Figure 2).


Figure 2. Preoperative cervical CT scan performed in extension, showing complete realignment. a) Sagittal plane. b) Coronal plane.

We preferred to perform a CT scan instead of a direct extension radiograph to better evaluate the right C1-C2 articulation complex. Surprisingly, CT scan showed a complete C1 mobility and a good realignment of both the odontoid process and the articular ones in the extension position. We performed a posterior fixation following the Goel-Harms technique. $[7,8]$ The patient was positioned with Mayfield holder and the upper cervical spine was manually realigned under direct radiographic guide. The procedure was performed in free hand technique, with direct radiographs guiding screw placement, and under neuromonitoring. A postoperative CT scan showed good stability of the system, with the tip of the left $\mathrm{C} 2$ pedicle screw slightly invading the transverse foramen (Figure 3 ). 

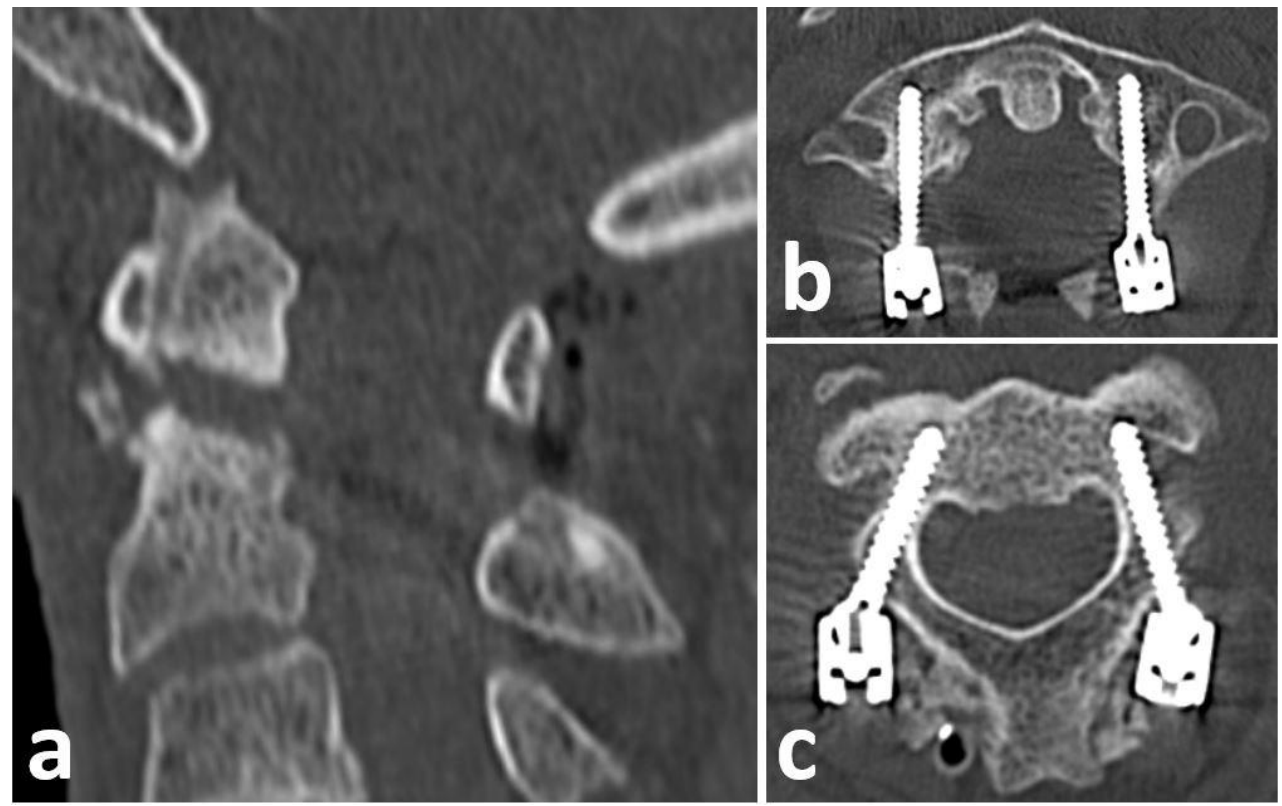

Figure 3. Postoperative cervical CT scan. a) Sagittal plane shoes good odontoid realignment. b) C1 axial view. c) C2 axial view, notice the tip of the right pedicle screw slightly invading the transverse foramen.

No complication was noticed, and the patient was discharged at home on POD 3 wearing a Miami J collar. Two weeks after surgery we managed to obtain the cervical CT scan performed in the foreign hospital 2 hours after the car accident, occurred 18 months earlier (Figure 4). Images showed an aligned type II Anderson fracture, in which a fixation (internal or external) could have reduced the risks of development the severe dislocation noticed 18 months later. At the 6 months follow-up the patient referred no deficits, reduction of neck pain, and imaging showed good stability of the instrumentation.
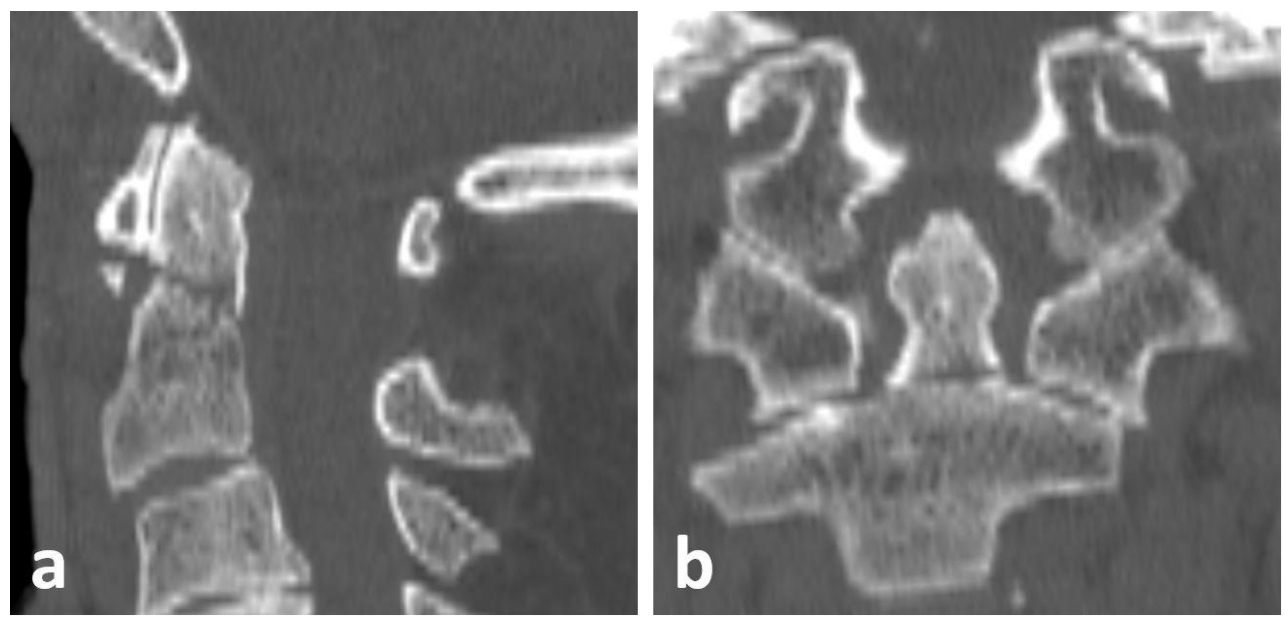

Figure 4. Cervical CT scan performed 2 hours after the trauma. a) On sagittal plane is visible the aligned Anderson type II fracture. b) On coronal plane, is too early to visualize the sclerotic remodelling of the right $\mathrm{C} 1-\mathrm{C} 2$ articulation.

\section{Discussion}

We want to briefly discuss the factors that led us to perform a Goel-Harms fixation.

We excluded the possibility to perform a trans-odontoid screw fixation, despite the favourable fracture line orientation. The main reason was that the fracture happened 18 
months earlier, and in CT scan it is clearly noticeable the sclerosis in the odontoid fracture margins, which can lead to extreme technical difficulties in placing an odontoid screw and it is associated with high rate of non-union.

Even though some surgeons prefer a trans-articular (TAS) technique in older age group for $\mathrm{C} 1-\mathrm{C} 2$ fixation, some authors found a higher incidence of vertebral artery injury and misplaced screws and a slightly lower rate of fusion with the TAS technique.[9]

These considerations and the higher confidence we have in performing a Goel-Harms fixation, led us to choose this kind of technique.

We found extremely useful the execution of a CT scan in both head-neck flexion and extension. We were convinced that the $\mathrm{C} 1-\mathrm{C} 2$ right articulation was completely fused in a wrong alignment, and this new exam helped us understanding the real dynamic condition of the upper cervical column and choosing the approach considering more elements.

\section{Conclusions}

Untreated type II odontoid fractures can lead to severe dislocation. In our case the signs of fusion of the right $\mathrm{C} 1-\mathrm{C} 2$ articular process could have led to choose an even more complex approach to realign the upper cervical spine. We chose to perform a CT scan to evaluate the right $\mathrm{C} 1-\mathrm{C} 2$ articulation in flexion and extension and we found the complete mobility of it. This allowed us to choose a classic posterior approach and instrumentation with the Goel-Harms technique. We want to highline both the importance of treating an Anderson type II fracture to prevent dislocation (acute or delayed), and the possibility to perform a flexion-extension CT scan to aid surgical planning.

Funding: This research received no external funding

Conflicts of Interest: The authors declare no conflict of interest.

\section{References}

[1] Iyer S, Hurlbert RJ, Albert TJ (2018) Management of odontoid fractures in the elderly: A review of the literature and an evidencebased treatment algorithm. Clin Neurosurg 82:419-430 . doi: 10.1093/neuros/nyx546

[2] Chapman J, Smith JS, Kopjar B, et al (2013) The AOSpine North America geriatric odontoid fracture mortality study: A retrospective review of mortality outcomes for operative versus nonoperative treatment of 322 patients with long-term followup. Spine (Phila. Pa. 1976). 38:1098-1104

[3] Butler JS, Dolan RT, Burbridge M, et al (2010) The long-term functional outcome of type II odontoid fractures managed nonoperatively. Eur Spine J 19:1635-1642 . doi: 10.1007/s00586-010-1391-0

[4] Aggarwal RA, Rathod AK, Chaudhary KS (2016) Irreducible atlanto-axial dislocation in neglected odontoid fracture treated with single stage anterior release and posterior instrumented fusion. Asian Spine J 10:349-354 . doi: 10.4184/asj.2016.10.2.349

[5] Klimov V, Kosimshoev M, Evsyukov A, et al (2020) Surgical treatment of neglected C2 odontoid process fracture with anterior atlantoaxial dislocation. Br J Neurosurg. doi: 10.1080/02688697.2020.1787340

[6] Riley DS, Barber MS, Kienle GS, et al (2017) CARE guidelines for case reports: explanation and elaboration document. J Clin Epidemiol 89:218-235 . doi: 10.1016/j.jclinepi.2017.04.026

[7] Goel A, Laheri V (1994) Plate and screw fixation for atlanto-axial subluxation. Acta Neurochir (Wien) 129:47-53 . doi: 10.1007/BF01400872

[8] Harms J, Melcher RP (2001) Posterior C1-C2 fusion with polyaxial screw and rod fixation. In: Spine. Spine (Phila Pa 1976), pp 2467-2471

[9] Elliott RE, Tanweer O, Boah A, et al (2014) Outcome comparison of atlantoaxial fusion with transarticular screws and screwrod constructs: Meta-analysis and review of literature. J. Spinal Disord. Tech. 27:11-28 